\section{Bluish-Black Pigmentation of the Sclera and the Aortic Valve in a Patient with Alkaptonuric Ochronosis}

\author{
Andreas Wilke', Otto Dapunt², Dietmar Steverding³
}

\begin{abstract}
A 69-year-old male patient was referred for evaluation of cardiac decompensation. He had previously been diagnosed with ochronosis (evident from bluish-black discoloration of the sclera of both eyes, Figure 1) and a degenerative valve defect with aortic, mitral and tricuspid valve insufficiency (evident from Doppler echocardiography). These were diagnostic clues to an ochronosis-associated valvular heart disease, and the patient was treated with an angiotensin-converting enzyme inhibitor to slow down the progression of valvular dysfunction. Further cardiac investigations revealed now that the function of the aortic valve had deteriorated such that replacement of the valve was inevitable. On operation, a bluishblack discoloration of the aortic valve (Figure 2, intraoperative view; at that time of operation the valve was already partially resected) and the aortic intima (Figure 3) was found. The bluish-black discoloration was due to the deposition of homogentisic acid, an intermediate catabolic product of the tyrosine metabolism which accumulates in ochronosis patients due to a lack of the enzyme homogentisic 1,2-dioxygenase. As seen here, the initial diagnosis of cardiovascular ochronosis was later confirmed by the requirement of aortic valve replacement.
\end{abstract}

\author{
Address for Correspondence \\ Andreas Wilke, MD \\ Kardiologische Praxis Papenburg \\ Hauptkanal links 100 \\ 26871 Papenburg \\ Germany \\ Phone (+49/4961) 9920-13, Fax -14 \\ e-mail:dr.andreas.wilke@googlemail.com
}

Dietmar Steverding, PhD

BioMedical Research Centre

School of Medicine, Health Policy and Practice

University of East Anglia

Norwich NR 47TJ

UK

Phone (+44/1603) 591-291, Fax -750

e-mail:dsteverding@hotmail.com
Figure 1. Bluish-black discoloration of the sclera of both eyes.

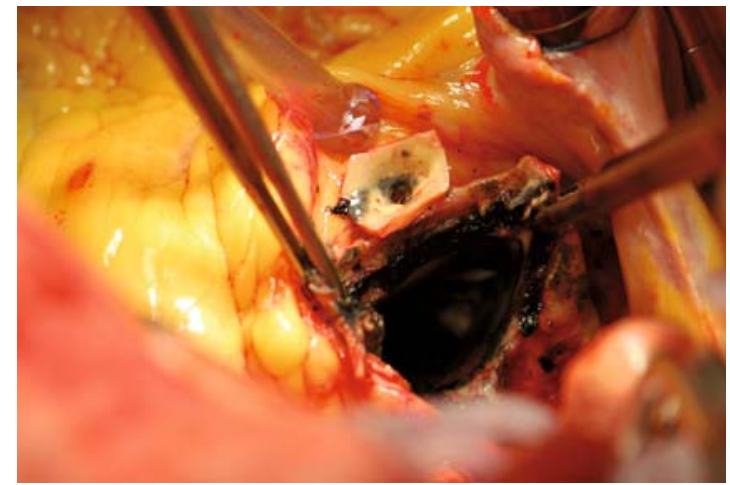

Figure 2. Intraoperative view: bluish-black discoloration of the aortic valve.

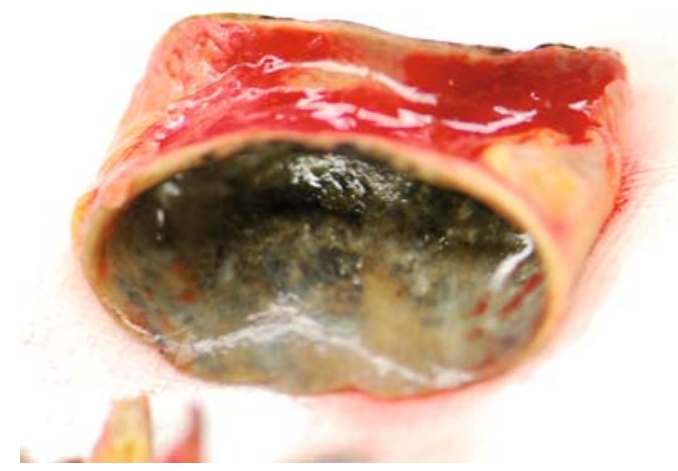

Figure 3. Bluish-black discoloration of the resected valve.

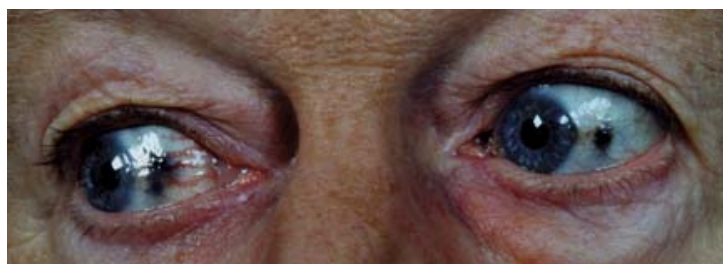

' Cardiologic Practice, Papenburg, Germany, ${ }^{2}$ Department of Cardiac Surgery, Klinikum Oldenburg gGmbH, Germany,

${ }^{3}$ BioMedical Research Centre, School of Medicine, Health Policy and Practice, University of East Anglia, Norwich, UK.

Herz 2010;35:41 DOI 10.1007/ s00059-010-3301-y 